\title{
Delusional parasitosis with hyperthyroidism in an elderly woman: a case report
}

\author{
Eylem Ozten ${ }^{1,2^{*}}$, Ali Evren Tufan ${ }^{3}$, Cem Cerit ${ }^{4}$, Gökben Hızlı Sayar ${ }^{1}$ and Irem Yalug Ulubil ${ }^{4}$
}

\begin{abstract}
Introduction: Delusional parasitosis is a rare, monosymptomatic psychosis involving a delusion of being infested with parasites. It is commonly observed among female patients over the age of 50. It is classified as a 'delusional disorder' according to the $10^{\text {th }}$ revision of the International Classification of Diseases and as a 'delusional disorder somatic type' according to the Diagnostic and Statistical Manual, Fourth Edition. Delusional parasitosis was reported to be associated with physical disorders such as hypoparathyroidism, Huntington's chorea and Alzheimer's disease, among others. Other than vitamin deficiencies however, a causal relationship has not to date been identified. We present this case due to the rarity of Turkish patients with this condition, its duration of follow-up, and its temporal pattern of symptoms paralleling thyroid function tests.
\end{abstract}

Case presentation: Our patient was a 70-year-old white Anatolian Turkish woman with primary school education who had been living alone for the past five years. She presented to our psychiatry department complaining of 'feeling large worms moving in her body'. The complaints started after she was diagnosed with hyperthyroidism, increased when she did not use her thyroid medications and remitted when she was compliant with treatment. She was treated with pimozide $2 \mathrm{mg} /$ day for 20 months and followed-up without any antipsychotic treatment for an additional nine months. At her last examination, she was euthyroid, not receiving antipsychotics and was not having any delusions.

Conclusion: Although endocrine disorders, including hyperthyroidism, are listed among the etiological factors contributing to secondary delusional parasitosis, as far as we are aware this is the first case demonstrating a temporal pattern of thyroid hyperfunction and delusions through a protracted period of follow-up. It may be that the treatment of delusional parasitosis depends on clarifying the etiology and that atypical antipsychotics may help in the management of primary delusional parasitosis. Further studies on the relationship between thyroid hormones and dopaminergic neurotransmission may be warranted.

\section{Introduction}

Delusional parasitosis (DP) is a monosymptomatic psychosis involving a delusion of being infested with parasites [1]. Patients with DP believe that insects, worms or other small pests live in their bodies and feed on them [2]. Visual or tactile hallucinations consistent with thought content can accompany the delusions. DP is typically observed in women over the age of 50 although isolated cases among men have been reported [1-3]. It can be classified as primary or secondary according to etiology.

\footnotetext{
*Correspondence: eylemozten@yahoo.com

${ }^{1}$ Department of Psychiatry, Uskudar University Medical Faculty, Istanbul,

Turkey

${ }^{2} N P$ İstanbul Nöropsikiyatri Hastanesi, Alemdağ Cad., Site Yolu, No: 29,

34768Umraniye, Istanbul, Turkey

Full list of author information is available at the end of the article
}

Primary DP is a psychiatric disorder whereas secondary DP is currently thought of as a symptom rather than a disorder. In the latter case, the delusion is secondary to another psychopathology or a medical illness [4,5].

Secondary DP has been associated with diseases and malignancies of the hematopoietic, pulmonary, cardiac, renal, gastrointestinal and endocrine systems, infections of the central nervous system, and nutritional deficiencies including vitamin B12, folate and pellagra [1-5]. However, the causal role of the underlying disorder has rarely been elucidated [1-5].

Although thought to be rare, the true prevalence of DP may be underestimated because patients do not believe the psychiatric origin of their complaints and are reluctant to apply for psychiatric treatment. Most cases 
are reported from Western countries with recent reports from Asia. Although the number of reported cases increases steadily, it remains a rare phenomenon. Here, we report the treatment of a patent with DP thought to be secondary to hyperthyroidism. This case was deemed worthy of presentation due to the scarcity of cases from Turkey, its duration of follow-up, and its temporal pattern of symptoms paralleling thyroid function tests.

\section{Case presentation}

Our patient was a 70-year-old white Anatolian Turkish woman with primary school education who had been living alone for the past five years. She presented to our Psychiatry Department complaining of 'feeling large worms moving in her body'. The complaint had been present for the past six months and started after she presented to an internist with complaints of weight loss, bilateral fine tremor of the upper extremities, shaking, sweating, palpitations and intolerance to heat. After the evaluation, she was hospitalized for a diagnostic work-up in our Endocrinology Department with a preliminary diagnosis of hyperthyroidism. Restlessness, increased speech and the feeling of 'large worms migrating through her body' were observed on the second day of hospitalization.

After psychiatric consultation, our patient was diagnosed with a psychotic disorder due to a general medical condition (hyperthyroidism). She was started on $2 \mathrm{mg} /$ day of haloperidol. This treatment was chosen because of the preliminary nature of the diagnosis and because our patient may have had delirium. Thyroid ultrasonography revealed five nodules measuring $2 \mathrm{~mm}$ to $5 \mathrm{~mm}$ in the left lobe and a heterogeneous nodule measuring $5 \mathrm{~mm}$ to $10 \mathrm{~mm}$ in the right lobe. None of the nodules displayed microcalcification, solidity or a reduced echogenicity pattern. The solitary nodule in the right lobe displayed an irregular contour. Lymphadenopathy and invasion of the neighboring structures were not noted. Scintigraphy revealed that all of the nodules were hyperfunctioning. She had no history of exposure to ionizing or environmental toxins, and no personal or family history of multiple endocrine neoplasia. A fine needle aspiration biopsy ruled out malignancy. The level of antibody to thyroid stimulating hormone receptor was found to be $2.5 \mathrm{IU} / \mathrm{L}$, thereby confirming Graves' disease.

As a result of the surgical consultation, medical follow-up was advised. On the third day, propylthiouracil $150 \mathrm{mg}$ /day and propranolol $30 \mathrm{mg} /$ day were started and the doses were maintained at $100 \mathrm{mg} /$ day and $40 \mathrm{mg} /$ day, respectively, after the first week. Restlessness, increased speech and DP remitted on the 10th day of treatment and haloperidol was stopped. She was discharged on the 20th day with a prescription of levothyroxine sodium $100 \mu \mathrm{g} /$ day (weight, $59 \mathrm{~kg}$; dose, $1.7 \mu \mathrm{g} / \mathrm{kg} /$ day). A fortnight after discharge, she started to feel the worms. After presenting to the Departments of
Dermatology, Microbiology and Infectious Diseases, Endocrinology, and Neurology, she was referred to the Department of Psychiatry and hospitalized. Her past medical and psychiatric histories were negative for pathology and her family history did not reveal evidence of psychopathology. She was teetotal and she was receiving no drugs or supplements at the time of evaluation other than levothyroxine sodium. She had no history of drug use or abuse and an inpatient follow-up lasting a month did not reveal any signs or symptoms of withdrawal.

At the baseline examination, she was noted to be cooperative and have reduced self-grooming. Her speech was fluent although restricted to the topic of tapeworms. Her mood and affect were anxious. She was orientated to people, space and time. Her attention, concentration and memory were within normal limits. She reported tactile hallucinations. Her judgment, reality testing and abstract thinking were impaired and her thought process was perseverative and circumferential. Her thought content was positive for somatic delusions. Motor retardation was observed while sleep and appetite were normal. Assessment with the Positive and Negative Syndrome Scale and Mini Mental State Examination revealed scores of 82 (positive: 19; negative: 18; general psychopathology: 45 ) and 28 , respectively.

Laboratory examinations including levels of vitamin B12, folate and ferritin, the Venereal Disease Research Laboratory test, and a toxicology screen were within normal limits other than elevated thyroid function tests (our patient was noncompliant with her levothyroxine treatment, Table 1). After an endocrinology consultation, it was advised that she be followed without medication for a month; thereafter, levothyroxine sodium $100 \mu \mathrm{g} /$ day was restarted. Consultations from the departments of Internal Medicine, Neurology, Hematology and Oncology ruled out the presence of an organic disorder. Electroencephalography and cranial magnetic resonance imaging were normal. Therefore our patient was diagnosed as having DP, presumably secondary to the hyperthyroidism. A baseline electrocardiogram (ECG) demonstrated a corrected QT interval (QTc) duration of 450ms. Previous ECGs revealed that her QTc duration varied between $440 \mathrm{~ms}$ and $490 \mathrm{~ms}$. Therefore, psychiatric treatment was initiated with pimozide $2 \mathrm{mg} /$ day and later the dose was titrated to $4 \mathrm{mg}$ / day. At the eighth week of treatment her thyroid function tests returned to normal limits along with a remission of the delusions. The QTc duration at this time was measured as $470 \mathrm{~ms}$. Our patient was discharged from the hospital and followed-up at the outpatient department. Her thyroid levels remained normal for a year and she was free of psychiatric symptoms. Therefore, pimozide was titrated down to $2 \mathrm{mg} /$ day. After 15 months her thyroid hormone levels increased again due to an irregular use of medication. Consequently, she began to feel the tapeworms again. 
Table 1 The relationship of thyroid function tests with positive and negative syndrome scale scores and psychiatric symptoms in a patient with delusional parasitosis

\begin{tabular}{|c|c|c|c|c|c|}
\hline Date & $\begin{array}{l}\text { Triiodothyronine } \\
\text { (ng/dL) }\end{array}$ & $\begin{array}{l}\text { Free thyroxine } \\
(\mathrm{ng} / \mathrm{dL})\end{array}$ & $\begin{array}{l}\text { Thyroid stimulating } \\
\text { hormone }^{c}(\mathrm{mlU} / \mathrm{L})\end{array}$ & Delusions & $\begin{array}{c}\text { PANSS } \\
\text { (positive/negative/general) }\end{array}$ \\
\hline Baseline $^{d}$ & 6.55 & 2.27 & 0.007 & + & $54(14 / 9 / 31)$ \\
\hline Month 6 & 7.95 & 3.97 & 0.005 & + & $82(19 / 18 / 45)$ \\
\hline Month 9 & 3.78 & 2.19 & 1.28 & - & $44(7 / 12 / 25)$ \\
\hline Month 15 & 3.56 & 1.97 & 1.32 & - & $38(7 / 8 / 23)$ \\
\hline Month 25 & 4.58 & 2.47 & 0.09 & + & $68(15 / 16 / 37)$ \\
\hline Month 29 & 3.97 & 2.07 & 1.02 & - & $34(7 / 7 / 20)$ \\
\hline
\end{tabular}

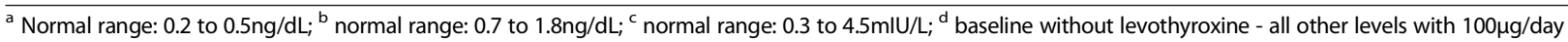
levothyroxine. PANSS: Positive and Negative Syndrome Scale.

Her complaints disappeared when her anti-thyroid medication was reinstituted. After 20 months of followup the pimozide was stopped and she was followed without antipsychotic treatment for an additional nine months. At her last examination she was euthyroid, not receiving antipsychotics and having no delusions.

\section{Discussion}

We have described a case of DP thought to be due to hyperthyroidism and reported its treatment and followup. Many individuals with DP are functional, with a minority being severely affected. The distress and loss of functionality reported in our patient shows that she was severely affected [1]. It has been reported that patients commonly present for general medical or dermatologic care, onset is insidious and most patients report symptoms lasting at least six months, the diagnosis may take years to establish, the belief of infestation may be shared, and that patients do not generally have a history of prior psychopathology but a history of social isolation [6,7]. These features were also present in our patient.

Hypochondriasis, dementia, mood and anxiety disorders, obsessive compulsive disorder and post-traumatic stress disorder were ruled out because of the intensity of conviction, her normal neurological and laboratory evaluations, the lack of previous history for psychiatric disorders and the absence of traumatic stressors in our patient.

Pimozide was used to treat our patient because, until recently, it was recommended for use in DP. However, it is currently not used as a first-line antipsychotic for patients with DP because of the risk of extrapyramidal symptoms, longer QTc interval and interactions with other drugs. Although our patient did not experience untoward side effects due to interactions with other agents or extrapyramidal side effects, follow-up ECGs revealed longer QTc intervals, illustrating the potential for cardiotoxicity. Several case reports have indicated the beneficial effects of atypical antipsychotics in primary DP, such as risperidone, quetiapine, olanzapine and amisulpride [6-10].
The use of haloperidol at $2 \mathrm{mg} /$ day at the initial presentation may be an important limitation of our case report. Haloperidol at this dose may not affect delusions and may lead to increased agitation. However, it was chosen at this time pending the results of laboratory tests and to rule out the presence of delirium. The current consensus is that pharmacological treatment of delirium is necessary if the patients pose a safety risk to themselves or others and that both typical and atypical antipsychotics are effective in the management of delirium, although they lack approval from the US Food and Drug Administration for this indication [11].

The pathogenesis of DP is currently unknown; proposed factors include recent awareness of a known disease via media or another individual, leading to amplification of somatic sensations; an elevation of extracellular dopamine within the striatum; social isolation; or stress [1-5,7]. Social isolation and stress of the diagnosis of hyperthyroidism may have played a role in our patient but the temporal relationship between thyroid hormone levels and the delusion of parasitosis (Table 1) may also point to a role of thyroid dysfunction in the development of delusion.

\section{Conclusion}

Although endocrine disorders, including hyperthyroidism, are listed among the etiological factors contributing to secondary DP, as far as we are aware this is the first case presentation demonstrating a temporal pattern of thyroid hyperfunction and delusions through a protracted period of follow-up. It may be that treatment of DP depends on clarifying the etiology and that atypical antipsychotics may help in the management of primary DP. Further studies on the relationship between thyroid hormones and dopaminergic neurotransmission may be warranted.

\section{Consent}

Written informed consent was obtained from the patient for publication of this case report and accompanying images. A copy of the written consent is available for review by the Editor-in-Chief of this journal. 


\section{Abbreviations}

DP: Delusional parasitosis; ECG: electrocardiography; QTc: corrected QT interval.

\section{Competing interests}

The authors declare that they have no competing interests.

\section{Authors' contributions}

$E O, C C, A E T, G H S$ and IYU diagnosed and followed the patient. AET and EO prepared the manuscript and CC, GHS and IYU evaluated the draft and suggested revisions. All authors read and approved the final manuscript.

\section{Author details}

'Department of Psychiatry, Uskudar University Medical Faculty, Istanbul, Turkey. ${ }^{2}$ NPIstanbul Nöropsikiyatri Hastanesi, Alemdağ Cad., Site Yolu, No: 29, 34768Umraniye, Istanbul, Turkey. ${ }^{3}$ Department of Child and Adolescent Psychiatry, Abant Izzet Baysal University, Medical Faculty, Bolu, Turkey.

${ }^{4}$ Department of Psychiatry, Kocaeli University Medical Faculty, Izmit, Turkey.

Received: 16 July 2012 Accepted: 30 November 2012

Published: 10 January 2013

\section{References}

1. Driscoll MS, Rothe MJ, Grant-Kels JM, Hale MS: Delusional parasitosis: a dermatologic, psychiatric and pharmacologic approach. J Am Acad Dermatol 1993, 29:1023-1033.

2. Ford EB, Calfee DP, Pearson RD: Delusions of intestinal parasitosis. South Med J 2001, 94:545-547.

3. Ait-Ameur A, Bern P, Firoloni MP, Menecier P: [Delusional parasitosis or Ekbom's syndrome]. Rev Med Interne 2000, 21:182-186.

4. Lyell A: The Michelson lecture: delusions of parasitosis. $\mathrm{Br} J$ Dermatol 1983, 108:485-499.

5. Barsky AJ, Borus JF: Functional somatic syndromes. Ann Intern Med 1999, 130:910-921.

6. Huber M, Kirchler E, Karner M, Pycha R: Delusional parasitosis and the dopamine transporter. A new insight of etiology? Med Hypotheses 2007, 68:1351-1358.

7. Lepping P, Russel I, Freudenmann RW: Antipsychotic treatment of primary delusional parasitosis: systematic review. Br J Psychiatry 2007, 191:198-205.

8. Gallucci G, Beard G: Risperidone and the treatment of delusions of parasitosis in an elderly patient. Psychosomatics 1995, 36:578-580.

9. Le K, Gonski PN: Delusional parasitosis mimicking cutaneous infestation in elderly patients. Med J Aust 2003, 179:209-210.

10. Lepping P, Gil-Candon R, Freudenmann RW: Delusional parasitosis treated with amisulpride. Prog Neurol Psychiatry 2005, 9:12-16.

11. Catic AG: Identification and management of in- hospital drug-induced delirium in older patients. Drugs Aging 2011, 28(9):737-748.

doi:10.1186/1752-1947-7-17

Cite this article as: Ozten et al:: Delusional parasitosis with

hyperthyroidism in an elderly woman: a case report. Journal of Medical Case Reports 2013 7:17.

\section{Submit your next manuscript to BioMed Central and take full advantage of:}

- Convenient online submission

- Thorough peer review

- No space constraints or color figure charges

- Immediate publication on acceptance

- Inclusion in PubMed, CAS, Scopus and Google Scholar

- Research which is freely available for redistribution 